\section{(6) OPEN ACCESS}

\title{
Lung function and airway obstruction: associations with circulating markers of cardiac function and incident heart failure in older men-the British Regional Heart Study
}

\author{
S Goya Wannamethee, ${ }^{1}$ A Gerald Shaper, ${ }^{1}$ Olia Papacosta, ${ }^{1}$ Lucy Lennon, ${ }^{1}$ \\ Paul Welsh, ${ }^{2}$ Peter $\mathrm{H}$ Whincup ${ }^{3}$
}

Department of Primary Care and Population Health, University College London, London, UK

${ }^{2}$ Institute of Cardiovascular \& Medical Sciences, BHF Glasgow Cardiovascular Research Centre, University of Glasgow, Glasgow, UK ${ }^{3}$ Division of Population Health Sciences and Education, Population Health Research Centre, St George's University of London, London, UK

\section{Correspondence to}

Professor S Goya

Wannamethee, Department of Primary Care and Population Health, UCL, Royal Free Campus, London NW3 2PF UK; g.wannamethee@ucl.ac.uk

Received 19 December 2014 Revised 19 November 2015 Accepted 23 November 2015 Published Online First 25 January 2016

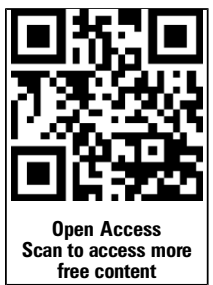

\section{SLinked}

- http://dx.doi.org/10.1136/ thoraxinl-2015-208119

\section{CrossMark}

To cite: Wannamethee SG, Shaper AG, Papacosta 0, et al. Thorax 2016;71: 526-534.

\section{ABSTRACT}

Aims The association between lung function and cardiac markers and heart failure (HF) has been little studied in the general older population. We have examined the association between lung function and airway obstruction with cardiac markers N-terminal probrain natriuretic peptide (NT-proBNP) and cardiac troponin $\mathrm{T}$ (cTnT) and risk of incident HF in older men. Methods and results Prospective study of 3242 men aged 60-79 years without prevalent HF or myocardial infarction followed up for an average period of 13 years, in whom 211 incident HF cases occurred. Incident HF was examined in relation to \% predicted FEV1 and FVC. The Global Initiative on Obstructive Lung Diseases spirometry criteria were used to define airway obstruction. Reduced FEV1, but not FVC in the normal range, was significantly associated with increased risk of $\mathrm{HF}$ after adjustment for established HF risk factors including inflammation. The adjusted HRs comparing men in the 6-24th percentile with the highest quartile were 1.91 (1.24 to 2.94) and 1.30 (0.86 to 1.96) for FEV1 and FVC, respectively. FEV1 and FVC were inversely associated with NT-proBNP and CTnT, although the association between FEV1 and incident $\mathrm{HF}$ remained after adjustment for NT-proBNP and CTnT. Compared with normal subjects (FEV1/FVC $\geq 0.70$ and $F V C \geq 80 \%$ ), moderate or severe (FEV1/FVC $<0.70$ and FEV1 $<80 \%$ ) airflow obstruction was independently associated with HF ((adjusted relative risk 1.59 (1.08 to 2.33)). Airflow restriction (FEV1/FVC $\geq 0.70$ and FVC $<80 \%$ ) was not independently associated with $\mathrm{HF}$.

Conclusions Reduced FEV1 reflecting airflow obstruction is associated with cardiac dysfunction and increased risk of incident HF in older men.

\section{INTRODUCTION}

COPD is common in the elderly and is associated with increased cardiovascular (CVD) morbidity and mortality. ${ }^{12}$ More recently, it has been established that COPD is common in patients with heart failure $(\mathrm{HF})$ and that patients with COPD are at increased risk of developing $\mathrm{HF}^{3}{ }^{4}$ The COPD-HF association could reflect shared common risk factors such as smoking, diabetes, obesity and inflammation. ${ }^{2} 35$ COPD has also been linked to cardiac stress and myocardial injury. ${ }^{6-9}$ The association between lung function and incident HF, in

\section{Key messages}

What is the key question?

- What is the association between reduced lung function and mild airflow obstruction with cardiac dysfunction and risk of incident heart failure (HF) in older people.

What is the bottom line?

- Reduced lung function reflecting moderate or severe airflow obstruction is associated with increased risk of $\mathrm{HF}$, which is to some extent associated with cardiac dysfunction.

\section{Why read on?}

- We have shown that the Global Initiative on Obstructive Lung Diseases criteria for defining airflow obstruction based on spirometry can lead to identification of older adults at high risk of $\mathrm{HF}$.

contrast to $\mathrm{CVD},{ }^{10}$ has been less studied at population level, especially among older people. However, a few prospective population studies have shown an association between reduced lung function as measured by the FEV1, vital capacity (VC) or the FEV1/FVC ratio and incident $\mathrm{HF}^{11-16}$ although this has not been observed in all studies. ${ }^{17}$ Reduced and low normal lung function measured by FEV1 has been associated with increased risk of $\mathrm{HF}^{14-16}$ independent of inflammatory markers. The Global Initiative for Chronic Obstructive Lung Diseases (GOLD) classification defines airflow obstruction by $\mathrm{FEV} / \mathrm{FVC}$ ratio $<0.70 .{ }^{18}$ However, normal ageing is associated with lung function declines that often lead to an FEV1/FVC ratio $<0.70$ for individuals over 65 years, which may lead to misclassification of airway obstruction. ${ }^{19}$ Although one study in the elderly has shown that a low FEV1/FVC ratio (lowest 5th percentile) is associated with increased HF risk, ${ }^{16}$ the risk associated with mild airflow obstruction in the older population is less clear and the relationship between airflow obstruction severity based on the spirometric GOLD classification of lung impairment ${ }^{18}$ and HF has not been studied in the older general population. 
High-sensitivity cardiac troponin $\mathrm{T}$ (cTnT), a biomarker of cardiomyocyte injury, and $\mathrm{N}$-terminal pro-brain natriuretic peptide (NT-proBNP), a marker of left ventricular wall stress, have both been associated with increased HF risk. ${ }^{20-22}$ NT-proBNP and cTnT have been shown to be raised in patients hospitalised with COPD. ${ }^{79}$ Whether such changes are seen in those with mild airflow obstruction or low normal lung function has been little studied in the general older population. We, therefore, examined the associations between pulmonary function and risk of HF in older men without prevalent myocardial infarction (MI) or HF and assessed to what extent the association is related to inflammation and cardiac dysfunction (NT-proBNP and cTnT). We have also examined the association between restrictive and obstructive ventilatory patterns with incident HF using a modification of the spirometric GOLD classification for lung function impairment. ${ }^{17}$

\section{SUBJECTS AND METHODS}

The British Regional Heart Study is a prospective study involving 7735 men aged 40-59 years drawn from one general practice in each of 24 British towns, who were screened between 1978 and $1980 .^{23}$ The population studied was socioeconomically representative and comprised predominantly white Europeans (>99\%). In 1998-2000, all surviving men, then aged 60-79 years, were invited for a 20th-year follow-up examination, on which the current analyses are based. All men completed a mailed questionnaire providing information on their lifestyle and medical history, had a physical examination and provided a fasting blood sample. The samples were frozen and stored at $-20^{\circ} \mathrm{C}$ on the day of collection and transferred in batches for storage at $-70^{\circ} \mathrm{C}$ until analysis, carried out after no more than one freeze-thaw cycle. The 12-lead ECGs were recorded using a Siemens Sicard 460 instrument and were analysed using Minnesota Coding definitions at the University of Glasgow ECG core laboratory. Men were asked whether a doctor had ever told them that they had angina or MI, HF or stroke; details of their medications were recorded at the examination including use of bronchodilators (British National Formulary code 3.1$)$. In total, 4252 men (77\% of available survivors) attended for examination. A total of 3706 men had lung function measures and blood measures of NT-proBNP and cTnT. We excluded men with prior HF or MI $(\mathrm{N}=464)$ at examination, leaving 3242 men for analysis.

\section{CVD risk factor measurements at 1998-2000}

Anthropometric measurements including body weight and height were carried out. Details of measurement and classification methods for smoking status, physical activity, social class, alcohol intake, blood pressure and blood lipids in this cohort have been described. ${ }^{24}{ }^{25}$ C-reactive protein (CRP) (marker of inflammation) was assayed by ultra sensitive nephelometry (Dade Behring, Milton Keynes, UK). NT-proBNP was determined using the Elecsys 2010 (Roche Diagnostics, Burgess Hill, UK). ${ }^{22}$ Troponin $\mathrm{T}$ was measured by a high-sensitivity method on an e411 (Roche Diagnostics, Burgess Hill, UK) using the manufacturer's calibrators and quality control material. The low control CV was 6.6\%, the high control CV 3.0\% and the assay limit of detection was $3 \mathrm{pg} / \mathrm{mL}$. Electrocardiographic left ventricular hypertrophy (LVH) was defined according to relevant Minnesota codes (codes 3.1 or 3.3). Atrial fibrillation (AF) was defined according to Minnesota codes 8.3.1 and 8.3.3.

\section{Lung function}

FEV1 and FVC were measured using a Vitalograph compact II spirometer with the subject seated. We used predictive equations for FEV1 and FVC derived from the general population Health Survey for England for males aged $>25$ years to obtain predicted lung function values taking account of age and height. ${ }^{26}$ The following equations were used:

$$
\begin{gathered}
\text { predicted FEV1 }=-\exp [-9.37674+0.000183 \times \text { age } \\
\left.-0.00011 \times \text { age }^{2}+\log (\text { height })\right] \\
\text { predictedFVC }= \\
\quad \exp [-10.36706+0.00434 \times \text { age }-0.00011 \\
\left.\times \text { age }^{2}+\log (\text { height })\right]
\end{gathered}
$$

Actual FEV1 and FVC were presented as a percentage of their predicted values. Percent predicted FEV1 (\%FEV1)=raw FEV1/ predicted FEV1 and per cent predicted FVC $(\% \mathrm{FVC})=$ raw FVC/predicted FVC. Abnormal FEV1 (FVC) was defined as men in the lowest 5 th percentile of the \%FEV (\%FVC) distribution. An FEV1/FVC ratio of $\geq 0.70$ was used to define airflow obstruction. We also initially divided the men into five lung pattern groups according to their FEV1/FVC ratio using a modification of the criteria developed by GOLD for defining the severity stages of airflow obstruction ${ }^{13}$ : severe airflow obstruction (FEV1/FVC $\geq 0.70$ and $\mathrm{FEV} 1<50 \%$ predicted), moderate airflow obstruction (FEV1/FVC $<0.70$ and FEV1 $\geq 50-<80 \%$ ), mild airflow obstruction (FEV1/FVC $<0.70$ and FEV1 $\geq 80 \%$ ), restricted (FEV1/FVC $\geq 0.70$ and FVC $<80 \%$ predicted) and normal (FEV1/FVC $\geq 0.70$ and $\mathrm{FVC} \geq 80 \%$ and not on bronchodilators).

\section{Follow-up}

All men were followed up from initial examination (19781980) for CVD morbidity ${ }^{27}$; 99\% follow-up has been achieved. In the present analyses, all-cause mortality and morbidity events are based on follow-up from re-examination in 1998-2000 to January 2012. Survival times ended at the first HF event or when they were censored for death due to any cause or at the end of the follow-up period (January 2012), whichever occurred first. Information on deaths was collected through the established 'tagging' procedures provided by the National Health Service registers. Fatal coronary heart disease (CHD) events were defined as death with CHD (International Classification of Diseases (ICD) 9th revision, codes 410-414) as the underlying code. A non-fatal MI was diagnosed according to WHO criteria. Evidence of non-fatal $\mathrm{MI}$ and $\mathrm{HF}$ was obtained by ad hoc reports from general practitioners supplemented by biennial reviews of the patients' practice records (including hospital and clinic correspondence) through to the end of the study period. Incident $\mathrm{CHD}$ included fatal CHD and non-fatal MI. Incident non-fatal HF was based on a doctor-confirmed diagnosis of HF from primary care medical records (including hospital and clinical correspondence). ${ }^{22}$ All cases were verified by a review of available clinical information from primary and secondary care records (symptoms, signs, investigations and treatment response) to ensure they are consistent with current recommendations on $\mathrm{HF}$ diagnosis. ${ }^{28}$ Incident fatal $\mathrm{HF}$ cases were those in which the diagnosis of HF was mentioned as the underlying cause of death at death certificates (ICD 9th revision code 428). Incident HF included both incident nonfatal and fatal HF. 


\section{Statistical methods}

The men were initially divided into equal quartiles based on the $\% \mathrm{FEV} 1$ and \%FVC distribution. Because of the interest in those with below normal lung function (lowest 5 th percentile), we separated the lowest 5 th percentile from the lowest quartile and five groups are used. The study had $80 \%$ power to detect a relative risk for HF of 1.6 comparing highest and lowest quartiles of lung function at $\mathrm{p}<0.05$. Tests for trends were carried out fitting FEV1 (FVC) in its original continuous form. Comparisons of baseline characteristics between the FEV1 groups were performed using the $\chi^{2}$ test for categorical variables and analysis of variance for continuous variables presented in table 1. The distributions of NT-proBNP, cTnT and CRP were skewed and $\log$ transformation was used to normalise these factors. All statistical testing was carried out on log NT-proBNP $\log \mathrm{cTnT}$ and $\log$ CRP. Geometric means were presented for logged variables. Linear regression was used to examine the associations between FEV1 (FVC), log NT-proBNP and log cTnT. Kaplan-Meier methods were used to calculate the cumulative $\mathrm{HF}$ incidence for five groups of \% predicted FEV1 and \% predicted FVC; the log-rank test was used to evaluate differences in the HF rates for these groups. Cox's proportional hazards model was used to assess the HR (relative risk) in a comparison of quarters of \%FEV1 and \%FVC. The proportional hazards assumption was examined using time-varying covariates, calculating interactions of predictor variables and a function of survival time and including them in the models. Examination of time-varying covariates indicated a violation of the proportionality assumption specifically among the men with abnormal FEV1 or FVC (lowest 5 percentiles) only. We carried out a sensitivity analysis excluding these men as well as truncating follow-up time to 8 years follow-up (the point at which the proportional hazards assumption held for FVC) to assess the robustness of the findings in the men with below normal lung function. We included confounding factors that are known to be associated with HF risk and that were associated with HF in this study in age-adjusted analyses. This included age, body mass index (BMI), social class, smoking, physical activity, heavy drinking, prevalent stroke, diabetes, use of antihypertensive treatment, systolic blood pressure, $\mathrm{LVH}$ and AF. In multivariable analyses, smoking (neversmokers, long-term ex-smokers ( $>15$ years), recent ex-smokers ( $<15$ years) and current smokers), social class (manual vs nonmanual), physical activity (four groups), diabetes (yes/no), prevalent stroke (yes/no), use of antihypertensive treatment (yes/no), heavy drinking (yes/no), LVH (yes/no) and AF (yes/no) were fitted as categorical variables. Systolic blood pressure, CRP, cTnT and NT-proBNP were fitted as continuous variables. To assess whether the association between lung function and incident HF may be due to the development of incident MI, which in turn results in increased risk of HF, we adjusted for incident CHD by fitting $\mathrm{CHD}$ as a time-dependent covariate.

\section{RESULTS}

\section{Baseline characteristics by FEV1}

Table 1 shows baseline characteristics in the study population by the five $\mathrm{FEV}_{1}$ groups. Poorer lung function was associated with several adverse CV risk factors including smoking, physical inactivity, diabetes, inflammation (CRP) and cardiac dysfunction (NT-proBNP, cTnT).

Table 1 Baseline characteristics by \% predicted $\mathrm{FEV}_{1}$ in 3242 men with no prior heart failure or myocardial infarction

\begin{tabular}{|c|c|c|c|c|c|c|}
\hline & \multicolumn{5}{|l|}{$\%$ predicted $\mathrm{FEV}_{\mathbf{1}}$} & \multirow[b]{2}{*}{$\begin{array}{l}\text { p Difference } \\
\text { between groups }\end{array}$} \\
\hline & $\begin{array}{l}\leq 5 \text { th } \\
\text { percentile }\end{array}$ & $\begin{array}{l}\text { 6-24th } \\
\text { percentile }\end{array}$ & $\begin{array}{l}\text { 25-49th } \\
\text { percentile }\end{array}$ & $\begin{array}{l}50-74 \text { th } \\
\text { percentile }\end{array}$ & $\begin{array}{l}\geq 75 \text { th } \\
\text { percentile }\end{array}$ & \\
\hline No. of men & 162 & 651 & 810 & 813 & 806 & \\
\hline Range FEV1, \% predicted & $<48.4$ & $48.4-75.0$ & $75.1-89.0$ & $89.1-101.6$ & $\geq 101.7$ & \\
\hline FEV (L) & $1.12(0.26)$ & $1.92(0.31)$ & $2.49(0.31)$ & $2.86(0.34)$ & $3.33(0.47)$ & \\
\hline FVC (L) & $2.12(0.09)$ & $2.77(0.06)$ & $3.27(0.06)$ & $3.64(0.06)$ & $4.13(0.07)$ & \\
\hline$\%$ FEV1/FVC $<0.7$ & 33.3 & 34.1 & 30.3 & 26.8 & 21.1 & \\
\hline \multicolumn{7}{|l|}{ Categorical variables (\%) } \\
\hline Smokers & 27.2 & 21.4 & 13.8 & 8.5 & 4.7 & $<0.001$ \\
\hline Manual & 63.6 & 62.5 & 54.0 & 51.3 & 45.8 & $<0.001$ \\
\hline Inactive & 54.4 & 39.0 & 31.6 & 30.8 & 26.2 & $<0.001$ \\
\hline Heavy drinkers & 6.2 & 5.2 & 3.2 & 4.2 & 3.0 & 0.083 \\
\hline Diabetes & 14.8 & 16.0 & 12.4 & 10.8 & 10.4 & 0.001 \\
\hline Stroke & 6.8 & 5.5 & 5.1 & 2.8 & 3.4 & 0.017 \\
\hline $\mathrm{AF}$ & 3.7 & 3.5 & 3.5 & 2.8 & 2.4 & 0.620 \\
\hline Antihypertensive use & 33.3 & 34.1 & 30.3 & 26.8 & 21.1 & $<0.001$ \\
\hline Left ventricular hypertrophy & 5.6 & 6.3 & 7.3 & 8.9 & 8.2 & 0.302 \\
\hline \multicolumn{7}{|l|}{ Continuous variables (means) } \\
\hline Age (years) & $69.4(5.4)$ & $69.1(5.4)$ & $68.0(5.2)$ & $67.8(5.5)$ & $68.9(5.7)$ & $<0.001$ \\
\hline $\mathrm{BMI}\left(\mathrm{kg} / \mathrm{m}^{2}\right)$ & $25.5(3.9)$ & $27.1(4.0)$ & $27.1(3.7)$ & $26.9(3.3)$ & $26.4(3.2)$ & $<0.001$ \\
\hline Systolic blood pressure $(\mathrm{mm} \mathrm{Hg})$ & $147.8(21.9)$ & $151.5(25.4)$ & $149.2(23.5)$ & $150.8(24.1)$ & $148.7(22.9)$ & 0.090 \\
\hline Cholesterol (mmol/L) & $5.86(1.10)$ & $5.93(1.02)$ & $6.10(1.10)$ & $6.09(1.04)$ & $6.09(1.06)$ & 0.002 \\
\hline High-density lipoprotein-cholesterol (mmol/L) & $1.41(0.41)$ & $1.31(0.35)$ & $1.32(0.34)$ & $1.31(0.33)$ & $1.36(0.33)$ & 0.002 \\
\hline C-reactive protein $(\mathrm{mg} / \mathrm{L})^{*}$ & $4.48(1.30-6.01)$ & $2.27(1.08-4.82)$ & $1.82(0.90-3.47)$ & $1.38(0.73-2.87)$ & $1.23(0.60-2.40)$ & $<0.001$ \\
\hline $\mathrm{N}$-terminal pro-brain natriuretic peptide $(\mathrm{pg} / \mathrm{mL})^{*}$ & $115.6(55-257)$ & $108.9(49-220)$ & $86.5(44-160)$ & 77.5 (38-147) & $80.6(41-146)$ & $<0.001$ \\
\hline Cardiac troponin $\mathrm{T}(\mathrm{pg} / \mathrm{mL})^{*}$ & $13.7(10.1-18.9)$ & $12.4(9.3-16.4)$ & $11.2(8.6-15.9)$ & $11.0(8.5-14.8)$ & $11.0(8.2-14.7)$ & $<0.001$ \\
\hline
\end{tabular}




\section{Lung function and cardiac markers}

Table 2 shows the associations between $\% \mathrm{FEV}_{1}, \% \mathrm{FVC}$ and cardiac markers adjusted for potential confounders and inflammation. $\% \mathrm{FEV}_{1}$ and, to a lesser extent, $\% \mathrm{FVC}$ were significantly associated with NT-proBNP. Strong inverse associations were seen between both $\% \mathrm{FEV}_{1}$ and $\% \mathrm{FVC}$ with $\mathrm{cTnT}$ after adjustment. However, when both were included in the model FEV1 related only to NT-proBNP, whereas FVC related only to cTnT.

\section{Lung function and incident $\mathrm{HF}$}

During the mean follow-up period of 13 years, there were 211 incident HF cases (rate 6.1/1000 person-years) in the 3242 men with no prior HF or MI at baseline. Figure 1 shows the cumulative incidence of $\mathrm{HF}$ by the five groups of $\% \mathrm{FEV}_{1}$ and $\% \mathrm{FVC}$ in these men. Risk of HF increased with decreasing \%FEV1 and \%FVC. Table 3 shows the association between lung function and incident HF, with adjustment for potential confounders and mediators. The increased risk associated with low lung function remained even after adjustment for age, smoking, physical activity, social class, alcohol intake, BMI, antihypertensive treatment, systolic blood pressure, prevalent diabetes, stroke, AF, LVH and CRP. Adjustment for NT-proBNP and cTnT attenuated the increased HF risk, but it remained significant in those in the lowest quartile within the normal range. Weaker associations were seen with FVC, with HF risk only elevated in those substantially below the normal range, but this was attenuated after adjustment for cardiac markers.

The same pattern of association was seen even when analyses were restricted to never-smokers and long-term ex-smokers ( $>20$ years since quitting) $(\mathrm{N}=2222 ; 138$ cases). Men with low normal FEV showed significantly increased risk after adjustment for confounders and CRP (model 2) (HR 2.00 (1.20 to 3.34)). The increased risk remained after adjustment for NT-proBNP and cTnT, though it was attenuated (HR 1.66, 95\% CI (0.99 to 2.78)). No association was seen with men with low normal FVC (HR $1.43,95 \%$ CI (0.86 to 2.38)) after adjustment for confounders and CRP (model 2).

Exclusion of men with abnormal FEV1 reduced the higher risk in those with low FVC even further. We also carried out sensitivity analysis truncating follow-up time to 8 years because of the violation of the proportional hazards in those with abnormal lung function with 13 years follow-up. Although the numbers were smaller ( $\mathrm{N}=137$ cases), the pattern of relation remained the same in that FVC showed no independent association after full adjustment (model 5) and the increased risk in those with abnormal FVC was markedly attenuated after adjustment for cardiac markers. The HR for those with abnormal FVC adjusted for the factors in model 1 was 2.88 (0.94 to 4.44), and this was attenuated to 1.33 (0.60 to 2.93) after full adjustment (model 5). For abnormal FEV1, the corresponding HR was 2.77 (1.26 to 6.09 ) and 1.99 (0.89 to 4.43 ), respectively. Men with low FEV1 in the 6th-24th percentile still showed significantly increased risk after full adjustment (model 5) (HR, 1.77 95\% CI (1.00 to 3.13)).

\section{Restrictive and obstructive lung function patterns Cardiac function}

Compared with the normal group, NT-proBNP was raised in men with moderate or severe airway obstruction but not in those with mild airway obstruction; CTnTwas only raised in those with severe airway obstruction (table 4). Both NT-proBNP and CTnT were raised in men with restrictive patterns even after adjustment for confounders.

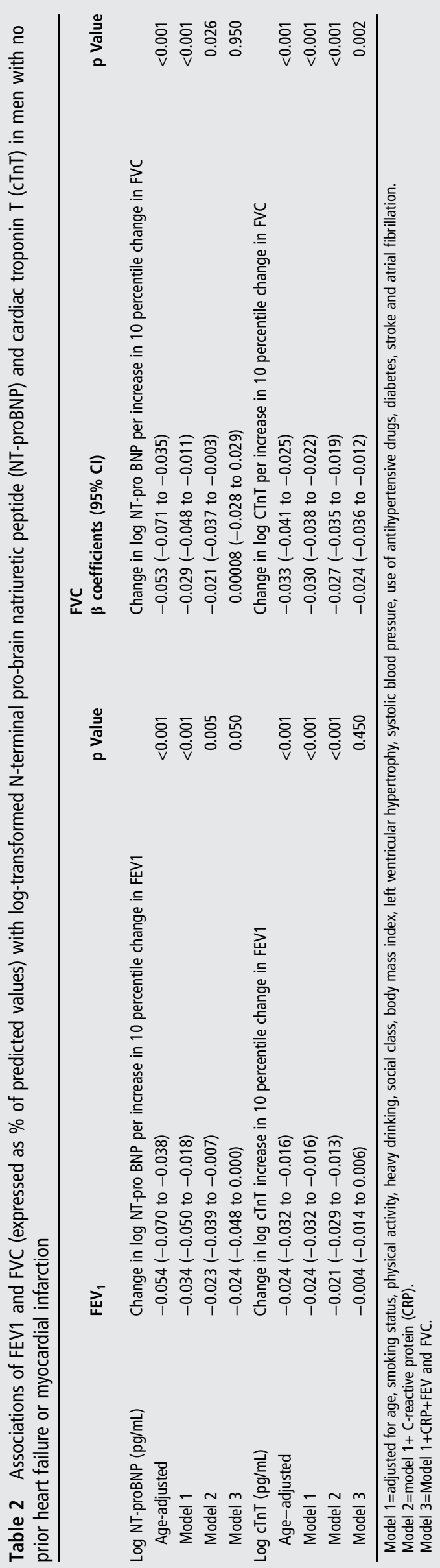


Figure 1 ( $A$ and $B)$ Cumulative heart failure (HF) incidence by five groups of $\%$ predicted $\mathrm{FEV} 1$ and $\%$ predicted FVC in 3242 men without prevalent myocardial infarction or HF.
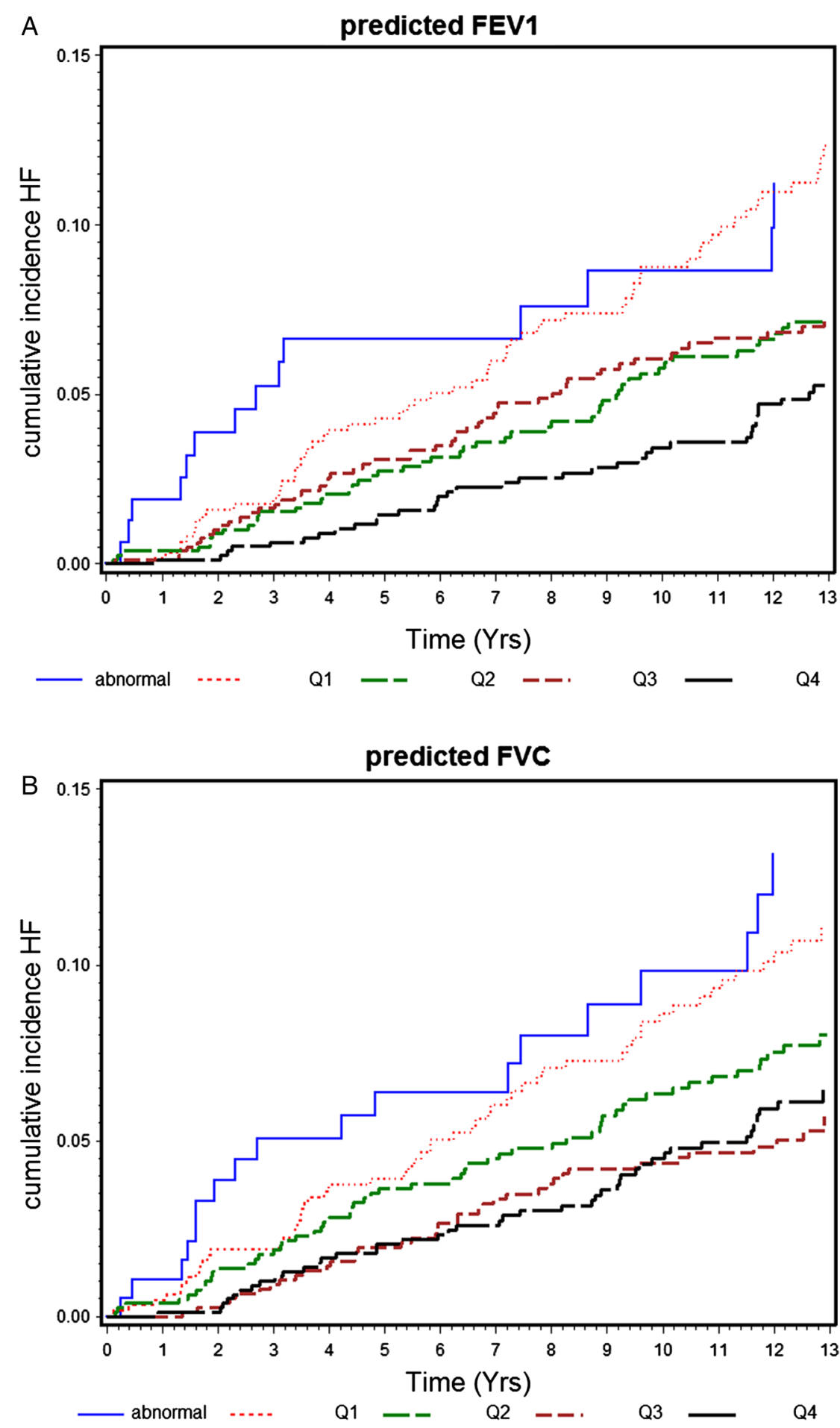

\section{Incident HF}

As the number of men with severe airflow obstruction was small and they showed similar risk to those with moderate airflow obstruction, we combined men with moderate and severe airflow obstruction and four groups are used (table 5). Restrictive lung impairment was associated with increased risk of HF, which was markedly attenuated after adjustment for $\mathrm{HF}$ risk factors and inflammation. HF risk was significantly increased in those with moderate or severe airflow obstruction (but not mild airflow obstruction) even after adjustment for established HF risk factors, CRP and cardiac markers (NT-proBNP and cTnT). Further adjustment for incident CHD made little difference. The increased risk seen was apparent even when those with severe obstruction were excluded (adjusted HR (model 5) 1.56 (1.03 to 2.37)).

\section{DISCUSSION}

In this study of older British men with no prior HF or MI, reduced FEV1 even within the low normal range was associated with increased HF risk after adjustment for a wide range of established HF risk factors and inflammation. Reduced FVC within the normal range, however, was not associated with increased risk of HF after adjustment; risk was only increased in those with exceptionally low FVC (lowest 5th percentile). Our 
Table 3 Adjusted $\mathrm{HR}(95 \% \mathrm{Cls}$ ) for incident heart failure (HF) in relation to \% predicted FEV1 and \% predicted FVC in men with no prior $\mathrm{HF}$ or myocardial infarction

\begin{tabular}{|c|c|c|c|c|c|c|}
\hline & Abnormal ( $\leq 5$ th percentile) & 6-24th percentile & 25-49th percentile & 50-74th percentile & $\geq 75$ th percentile & p Trend \\
\hline \multicolumn{7}{|l|}{$\%$ predicted FEV } \\
\hline No. of men & 162 & 651 & 810 & 813 & 806 & \\
\hline Rate/1000 (n) & $10.1(14)$ & $9.4(60)$ & $5.7(49)$ & $5.9(52)$ & $4.0(36)$ & \\
\hline Age-adjusted & 2.76 (1.49 to 5.12$)$ & 2.44 (1.61 to 3.69$)$ & 1.59 (1.03 to 2.45$)$ & 1.64 (1.07 to 2.51$)$ & 1.00 & $<0.001$ \\
\hline Model 1 & $2.19(1.14$ to 4.21$)$ & 1.96 (1.27 to 3.02$)$ & 1.34 (0.89 to 2.08$)$ & $1.45(0.94$ to 2.23$)$ & 1.00 & 0.002 \\
\hline Model 2 & 2.10 (1.10 to 4.05$)$ & 1.91 (1.24 to 2.94$)$ & 1.31 (0.84 to 2.03$)$ & $1.43(0.93$ to 2.19$)$ & 1.00 & 0.004 \\
\hline Model 3 & $1.87(0.97$ to 3.60$)$ & 1.70 (1.10 to 2.63$)$ & 1.25 (0.80 to 1.93$)$ & $1.36(0.89$ to 2.10$)$ & 1.00 & 0.016 \\
\hline Model 4 & $1.78(0.93$ to 3.44$)$ & 1.72 (1.11 to 2.65$)$ & $1.18(0.76$ to 1.84$)$ & $1.41(0.92$ to 2.13$)$ & 1.00 & 0.024 \\
\hline Model 5 & $1.63(0.84$ to 3.19$)$ & 1.61 (1.04 to 2.49 ) & $1.17(0.75$ to 1.82$)$ & 1.35 (0.88 to 2.07$)$ & 1.00 & 0.047 \\
\hline \multicolumn{7}{|l|}{$\%$ predicted FVC } \\
\hline No. of men & 164 & 649 & 813 & 807 & 811 & \\
\hline Rate/1000 (n) & $11.3(16)$ & $8.8(56)$ & $6.4(56)$ & $4.5(38)$ & $4.9(45)$ & \\
\hline Age-adjusted & 2.29 (1.37 to 4.18$)$ & 1.80 (1.22 to 2.67$)$ & 1.38 (0.93 to 2.04$)$ & 0.91 (0.59 to 1.40$)$ & 1.00 & $<0.001$ \\
\hline Model 1 & $1.78(0.98$ to 3.22$)$ & $1.33(0.88$ to 2.00$)$ & $1.14(0.77$ to 1.70$)$ & $0.80(0.52$ to 1.23$)$ & 1.00 & 0.083 \\
\hline Model 2 & $1.68(0.92$ to 3.05$)$ & $1.30(0.86$ to 1.96$)$ & $1.13(0.76$ to 1.68$)$ & $0.79(0.31$ to 1.22$)$ & 1.00 & 0.121 \\
\hline Model 3 & $1.50(0.82$ to 2.75$)$ & $1.33(0.88$ to 2.00$)$ & $1.11(0.74$ to 1.65$)$ & $0.84(0.55$ to 1.31$)$ & 1.00 & 0.213 \\
\hline Model 4 & $1.46(0.80$ to 2.67$)$ & 1.18 (0.79 to 1.78$)$ & 1.07 (0.71 to 1.59$)$ & $0.77(0.50$ to 1.20$)$ & 1.00 & 0.386 \\
\hline Model 5 & 1.29 (0.69 to 2.39$)$ & 1.25 (0.83 to 1.88$)$ & 1.07 (0.72 to 1.60$)$ & $0.83(0.53$ to 1.20$)$ & 1.00 & 0.453 \\
\hline
\end{tabular}

findings confirm previous studies in middle-aged and older populations showing an inverse association between FEV1 and incident HF. ${ }^{14-16}$ The findings were more evident for airflow obstruction airways rather than restrictive lung impairment. Our findings extend previous studies by examining the association with cardiac markers NT-proBNP and cTnT not previously assessed and examining the spirometric GOLD criteria for obstructive airways in relation to $\mathrm{HF}$ risk in an elderly population.

\section{Lung function and incident $\mathrm{HF}$}

The increased HF risk associated with reduced FEV1 in this study was not explained by established HF risk factors known to be associated with lung function, including $\mathrm{LVH}$ and $\mathrm{AF}^{29-31}$

Table 4 Mean lung function and the difference in mean level of $\log N$ terminal pro-brain natriuretic peptide (NT-proBNP) and log cardiac troponin $\mathrm{T}(\mathrm{cTnT})$ in men with restrictive and obstructive lung patterns compared with men with normal lung pattern in men with no prior heart failure or myocardial infarction

\begin{tabular}{|c|c|c|c|c|c|}
\hline & \multirow[b]{2}{*}{$\begin{array}{l}\text { Normal } \\
\mathrm{N}=1582\end{array}$} & \multirow[b]{2}{*}{$\begin{array}{l}\text { Restrictive } \\
\mathrm{N}=887\end{array}$} & \multicolumn{3}{|l|}{ Obstructive } \\
\hline & & & $\begin{array}{l}\text { Mild } \\
\mathrm{N}=235\end{array}$ & $\begin{array}{l}\text { Moderate } \\
\mathrm{N}=351\end{array}$ & $\begin{array}{l}\text { Severe } \\
\mathrm{N}=137\end{array}$ \\
\hline Mean FEV1,\% predicted & 101 & 75 & 95 & 66 & 39 \\
\hline Range, \% & 74-193 & $15-106$ & $88-219$ & $55-122$ & 29-125 \\
\hline Mean FEV1(SD), L & $3.04(0.48)$ & $2.25(0.49)$ & $2.80(0.53)$ & $1.96(0.34)$ & $1.14(0.27)$ \\
\hline Mean FVC, \% Predicted & 96 & 67 & 101 & 83 & 61 \\
\hline Range, \% & $80-156$ & $12-79$ & $88-219$ & $55-122$ & $29-125$ \\
\hline \multirow[t]{2}{*}{ Mean FVC (SD), L } & $3.82(0.59)$ & $2.67(0.56)$ & $4.32(0.80)$ & $3.25(0.61)$ & $2.39(0.83)$ \\
\hline & & \multicolumn{3}{|c|}{ Mean difference $(95 \% \mathrm{Cl})$ in log NT-proBNP (pg/mL) } & \\
\hline Age-adjusted & 0 & $0.16(0.08 \text { to } 0.24)^{*}$ & $-0.03(-0.17$ to 0.11$)$ & $0.20(0.19 \text { to } 0.11)^{*}$ & $0.21(0.04 \text { to } 0.39)^{*}$ \\
\hline Model 1 & 0 & $0.12(0.04 \text { to } 0.20)^{*}$ & $-0.05(-0.17$ to 0.08$)$ & $0.16(0.05 \text { to } 0.27)^{*}$ & $0.17(0.01 \text { to } 0.32)^{*}$ \\
\hline \multirow[t]{2}{*}{ Model 2} & 0 & $0.08(0.003 \text { to } 0.16)^{*}$ & $-0.06(-0.19$ to 0.07$)$ & $0.11(0.002 \text { to } 0.22)^{*}$ & $0.08(-0.09$ to 0.25$)$ \\
\hline & & \multicolumn{2}{|c|}{ Mean difference $(95 \% \mathrm{Cl})$ in $\log \mathrm{cTnT}(\mathrm{pg} / \mathrm{mL}))$} & & \\
\hline Age-adjusted & 0 & $0.10(0.07 \text { to } 0.14)^{*}$ & $-0.02(-0.08$ to 0.37$)$ & $0.00(-0.05$ to 0.05$)$ & $0.11(0.04 \text { to } 0.19)^{*}$ \\
\hline Model 1 & 0 & $0.08(0.06 \text { to } 0.10)^{*}$ & $-0.02(-0.08$ to 0.04$)$ & $-0.01(-0.05$ to 0.04$)$ & $0.11(0.04 \text { to } 0.19)^{*}$ \\
\hline Model 2 & 0 & $0.07(0.05 \text { to } 0.09)^{*}$ & $-0.02(-0.08$ to 0.04$)$ & $-0.01(-0.06$ to 0.04$)$ & $0.08(0.004 \text { to } 0.16)^{*}$ \\
\hline
\end{tabular}


Table 5 Adjusted HR (95\% Cls) for incident heart failure (HF) in relation to restrictive and obstructive lung patterns in men with no prior HF or myocardial infarction

\begin{tabular}{|c|c|c|c|c|}
\hline & $\begin{array}{l}\text { Normal } \\
N=1582\end{array}$ & $\begin{array}{l}\text { Restrictive } \\
\mathrm{N}=887\end{array}$ & $\begin{array}{l}\text { Mild } \\
\mathrm{N}=235\end{array}$ & $\begin{array}{l}\text { Moderate/severe\# } \\
\mathrm{N}=488\end{array}$ \\
\hline \multicolumn{5}{|l|}{ Incident HF } \\
\hline Rate/1000 (n) & $4.6(81)$ & $7.5(67)$ & $5.1(13)$ & $9.2(43)$ \\
\hline Age-adjusted & 1.00 & 1.59 (1.15 to 2.19$)$ & $0.93(0.52$ to 1.68$)$ & $1.86(1.28$ to 2.69$)$ \\
\hline Model 1 & 1.00 & 1.35 (0.97 to 1.88$)$ & 1.00 (0.56 to 1.82$)$ & 1.70 (1.16 to 2.50$)$ \\
\hline Model 2 & 1.00 & $1.32(0.94$ to 1.84$)$ & $0.98(0.54$ to 1.77$)$ & 1.67 (1.14 to 2.46$)$ \\
\hline Model 3 & 1.00 & $1.24(0.89$ to 1.73$)$ & $0.92(0.51$ to 1.68$)$ & 1.58 (1.07 to 2.33$)$ \\
\hline Model 4 & 1.00 & $1.19(0.85$ to 1.68$)$ & $0.99(0.55$ to 1.79$)$ & $1.66(1.13$ to 2.45$)$ \\
\hline Model 5 & 1.00 & $1.15(0.82$ to 1.62$)$ & $0.93(0.51$ to 1.68$)$ & 1.59 (1.08 to 2.33$)$ \\
\hline \multicolumn{5}{|c|}{$\begin{array}{l}\text { Model } 1=\text { adjusted for age, smoking status, physical activity, heavy drinkin } \\
\text { drugs, diabetes, stroke and atrial fibrillation. } \\
\text { Model } 2=\text { model } 1+\mathrm{C} \text {-reactive protein. } \\
\text { Model } 3=\text { model } 2+\mathrm{N} \text {-terminal pro-brain natriuretic peptide (NT-proBNP). } \\
\text { Model } 4=\text { model } 2+\text { cardiac troponin T (cTnT). } \\
\text { Model } 5=\text { model } 2+\mathrm{NT} \text {-proBNP+cTnT. } \\
{ }^{*} \text { Moderate and severe group were combined due to small numbers. }\end{array}$} \\
\hline
\end{tabular}

which is consistent with findings from the Cardiovascular Health Study. ${ }^{12}$ The association between FEV1 and HF was independent of inflammatory markers CRP and interleukin-6 and adjustment for incident CHD did not alter the findings as shown in other studies. ${ }^{12} 1415$ Shortness of breath and low lung function is a symptom of both COPD and HF. There is thus the possibility that poor lung function is reflecting preclinical HF. However, we were able to adjust for cardiac markers of HF including NT-proBNP and cTnT and the association between low FEV1 and HF persisted after these adjustments. Although reduced FVC (reflecting restrictive patterns of lung disease) was associated with HF, this was markedly attenuated after adjustment for established HF risk factors. The lack of association between FVC and HF is unlikely to be the result of competing non-cardiac causes as FVC and FEV1 were both related to noncardiac causes and censoring for non-cardiac causes had only minimal effect.

\section{Restrictive and obstructive patterns and incident $\mathrm{HF}$}

Although a few population studies have shown associations between both restrictive and obstructive lung function patterns and HF after adjustment for established HF risk factors, ${ }^{14} 15$ we have observed a weaker association between restrictive lung function patterns and risk of $\mathrm{HF}$ than with obstructive patterns, consistent with the weaker findings seen for FVC than the FEV1. Restrictive lung function patterns (FEV1/FVC $>0.70$ and predicted $\mathrm{FVC}<80 \%$ ) were common in this elderly study population $(27 \%)$ but were not associated with increased risk of HF after adjustment for established HF risk factors. Normal ageing is strongly associated with lower FVC and reduced FVC may not actively identify true pulmonary restriction in the elderly. ${ }^{32}$ Although low FVC may identify restrictive lung patterns in the elderly in the presence of a normal FEV1/FVC ratio $(>0.7)$, few men had normal FEV1/FVC and a low FVC in this study and we did not have the power to detect a significant difference in this group. In contrast, moderate or severe airway obstruction (FEV1/FVC ratio $<0.7$ and FEV1 $<80 \%$ ) was significantly associated with increased HF risk, an increase that was not explained by established risk factors or inflammation. Mild airway obstruction was not associated with increased risk; this may relate to the fact that mild obstruction had no effect on cardiac function as was seen in men with moderate/severe airway obstruction.

\section{Reduced lung function and cardiac dysfunction}

We have shown strong inverse associations between both FEV1 and FVC and cTnT and NT-proBNP. Increased levels of cTnT were more strongly associated with restrictive lung function patterns and were only markedly raised in the small group of men with very severe airways obstruction, consistent with the findings of studies in hospitalised patients with COPD. ${ }^{6-9}$ NT-proBNP was, however, related to both obstructive and restrictive airway patterns. NT-proBNP is released from cardiac myocytes in response to increased ventricular wall stress and cardiac dysfunction. ${ }^{33}$ Several mechanisms could explain the increased NT-proBNP in subjects with COPD. Airway obstruction decreases expiratory flow rates and causes lung hyperinflation, which is associated with decreased cardiac function and may increase NT-proBNP. ${ }^{6}$ NT-proBNP may also be elevated due to pulmonary hypertension and right ventricular dysfunction caused by pulmonary arterial pressure overload. ${ }^{34} 35$ Early right ventricular structural abnormalities could ultimately lead to a deterioration of left ventricular function and clinical HF.

The association between reduced FEV1 airway obstruction and incident HF was partially attenuated by adjustment for baseline NT-proBNP and cTnT, although risk still remained significantly increased. Although NT-proBNP and cTnT contribute to the association between airflow obstruction and HF risk, other mechanisms including oxidative stress have also been implicated. $^{16}$

\section{STRENGTHS AND LIMITATIONS}

The strength of the study is as a representative cohort with good standardised lung function measures with a wide range of HF risk factors measured. However, it was based on an older, predominantly white male population of European extraction, so that the results cannot be generalised directly to women, younger populations or other ethnic groups. Like most epidemiological studies, we did not have post-bronchodilator lung function, which is used for the strict classification using GOLD criteria. Nevertheless, using the criteria for moderate or severe airway obstruction based on pre- bronchodilator lung function, 
we have shown airway obstruction to be associated with increased HF risk. The current findings are based on doctordiagnosed HF, which may underestimate the true incidence of HF in this study population. However, the determinants of HF in this study population (including obesity, NT-proBNP, social class and heavy drinking) $)^{22} 243637$ generally accord with prior data and suggest that the HF outcome used was valid. Adjustments were based on measurements at examination, and we had no information on incident AF, which is associated with reduced lung function and HF risk. Information on echocardiogram measurements was not available in all men, and we were not, therefore, able to differentiate systolic and diastolic HF.

\section{CONCLUSION}

Reduced FEV1, reflecting moderate or severe airflow obstruction, is associated with elevated levels of cardiac dysfunction and increased risk of HF in older men. The use of GOLD criteria for defining airflow obstruction based on spirometry can lead to identification of older adults at high risk of $\mathrm{HF}$. Spirometry measurements might be considered in clinical practice to identify older people at high risk of developing HF who may benefit from further cardiac investigations and potentially benefit from early interventions.

Contributors SGW initiated the concept and design of the paper, analysed the data and drafted the manuscript. PW, PHW and AGS contributed to the interpretation of data. OP contributed to the analysis of the paper. PW, LL and PHW contributed to the acquisition of the data. All authors revised it critically for important intellectual content and approved the final version of the manuscript. SGW is the guarantor for the manuscript and has full access to all the data in the study and takes responsibility for the integrity of the data and the accuracy of the data analysis.

Funding The British Regional Heart Study is a Research Group supported by the British Heart Foundation (BHF) Programme grant (RG/13/16/30528). Paul Welsh is supported by a BHF intermediate fellowship FS/12/62/29889.

Competing interests None declared.

Patient consent Obtained.

Ethics approval The National Research Ethics Committee.

Provenance and peer review Not commissioned; externally peer reviewed.

Data sharing statement Requests for data are considered by the British Regional Heart Study Committee group. For general data sharing enquiries, please contact Lucy Lennon I.lennon@ucl.ac.uk.

Open Access This is an Open Access article distributed in accordance with the terms of the Creative Commons Attribution (CC BY 4.0) license, which permits others to distribute, remix, adapt and build upon this work, for commercial use, provided the original work is properly cited. See: http://creativecommons.org/ licenses/by/4.0/

\section{REFERENCES}

1 Müllerova $\mathrm{H}$, Agusti $\mathrm{A}$, Erqou $\mathrm{S}$, et al. Cardiovascular comorbidity in COPD: systematic literature review. Chest 2013;144:1163-78.

2 Maclay JD, MacNee W. Cardiovascular disease in COPD: mechanisms. Chest 2013;143:798-807.

3 Hawkins NM, Virani S, Ceconi C. Heart failure and chronic obstructive pulmonary disease: the challenges facing physicians and health services. Eur Heart J 2013;34:2795-803.

4 de Miguel Diez J, Chancafe Morgan J, Jiménez García R. The association between COPD and heart failure:a review. Int J COPD 2013;8:305-12.

5 Gan WQ, Man SF, Senthilselvan A, et al. Association between chronic obstructive pulmonary disease and systemic inflammation: a systematic review and a meta-analysis. Thorax 2004;59:574-80.

6 Wieshammer S, Dreyhaupt J, Basler B. A link between impaired lung function and increased cardiac stress. Respiration 2010;79:355-62.

7 Patel AR, Kowlessar BS, Donaldson GC, et al. Cardiovascular risk, myocardial injury, and exacerbations of chronic obstructive pulmonary disease. Am J Respir Crit Care Med 2013;188:1091-9.
8 Neukamm AMC, Høiseth AD, Hagve T, et al. High-sensitivity cardiac troponin T levels are increased in stable COPD. Heart 2013;99:382-7.

9 Chi SY, Kim EY, Ban HJ, et al. Plasma N-terminal pro-brain natriuretic peptide: a prognostic marker in patients with chronic obstructive pulmonary disease. Lung 2012;190:271-6.

10 Sin DD, Wu L, Man SF. The relationship between reduced lung function and cardiovascular mortality: a population-based study and a systematic review of the literature. Chest 2005;127:1952-9.

11 Kannel WB, Seidman JM, Fercho W, et al. Vital capacity and congestive heart failure: The Framingham Study. Circulation 1974;49:1160-6.

12 Gottdiener JS, Arnold AM, Aurigemma GP, et al. Predictors of congestive heart failure in the elderly: the Cardiovascular Health Study. J Am Coll Cardiol 2000:35:1628-37.

13 Lam CS, Lyass A, Kraigher-Krainer E, et al. Cardiac dysfunction and noncardiac dysfunction as precursors of heart failure with reduced and preserved ejection fraction in the community. Circulation 2011;124:24-30.

14 Engström G, Melander O, Hedblad B. Population-based study of lung function and incidence of heart failure hospitalisations. Thorax 2010;65:633-8.

15 Agarwal SK, Heiss G, Barr RG, et al. Airflow obstruction, lung function, and risk of incident heart failure: the Atherosclerosis Risk in Communities (ARIC) study. Eur J Heart Fail 2012;14:414-22.

16 Georgiopoulou VV, Kalogeropoulos AP, Psaty BM, et al. Lung function and risk for heart failure among older adults: the Health $\mathrm{ABC}$ Study. Am J Med 2011:124:334-41.

17 Eriksson $H$, Svardsudd K, Larsson B, et al. Risk factors for heart failure in the general population: the study of men born 1913. Eur Heart J 1989;10: 647-56.

18 Pauwels RA, Buist AS, Ma P, et al, GOLD Scientific Committee. Global strategy for the diagnosis, management, and prevention of chronic obstructive pulmonary disease: National Heart, Lung, and Blood Institute and World Health Organization Global Initiative for Chronic Obstructive Lung Disease (GOLD): executive summary. Respir Care 2001;46:798-825.

19 Hansen JE, Sun XG, Wasserman K. Spirometric criteria for airway obstruction: Use percentage of FEV1/FVC ratio below the fifth percentile, not $<70 \%$. Chest 2007:131:349-55.

20 deFilippi $\mathrm{CR}$, de Lemos JA, Christenson RH, et al. Association of serial measures of cardiac troponin $T$ using a sensitive assay with incident heart failure and cardiovascular mortality in older adults. JAMA 2010;304:2494-502.

21 de Lemos JA, Drazner MH, Omland T, et al. Association of troponin T detected with a highly sensitive assay and cardiac structure and mortality risk in the general population. JAMA 2010;304:2503-12.

22 Wannamethee SG, Welsh $\mathrm{P}$, Whincup $\mathrm{P}$, et al. N-terminal pro brain natriuretic peptide but not copeptin improves prediction of heart failure over other routine clinical risk parameters in older men with and without cardiovascular disease: population-based study. Eur J Heart Fail 2014;16:25-32.

23 Shaper AG, Pocock SJ, Walker M, et al. British Regional Heart Study: cardiovascular risk factors in middle-aged men in 24 towns. BMJ 1981;283:179-86.

24 Wannamethee SG, Shaper AG, Whincup PH, et al. Obesity and risk of incident heart failure in older men with and without pre-existing coronary heart disease: does leptin have a role?' J Am Coll Cardiol 2011;58:1870-7.

25 Wannamethee SG, Lowe GDO, Whincup PH, et al. Physical activity and hemostatic and inflammatory variables in elderly men. Circulation 2002;105:1785-90.

26 Falaschetti $\mathrm{E}$, Laiho J, Primatesta $\mathrm{P}$, et al. Prediction equations for normal and low lung function from the health Survey for England. Eur Respir J 2004;23:456-463.

27 Walker M, Shaper AG, Lennon L, et al. Twenty year follow-up of a cohort study based in general practices in 24 British towns. J Publ H/th Med 2000;22:479-85

28 McMurray JJV, Adamopoulos S, Anker SD, et al, ESC Committee for Practice Guidelines (CPG), Document Review. ESC Guidelines for the diagnosis and treatment of acute and chronic heart failure 2012: The Task Force for the Diagnosis and Treatment of Acute and Chronic Heart Failure 2012 of the European Society of Cardiology. Developed in collaboration with t the Heart Failure Association (HFA) of the ESC. Eur Heart J 2012:33:1787-847.

29 Enright PL, Kronmal RA, Smith VE, et al. Reduced vital capacity in elderly persons with hypertension, coronary heart disease, or left ventricular hypertrophy. The Cardiovascular Health Study. Chest 1995;107:28-35.

30 Ford ES, Wheaton AG, Mannino DM, et al. Elevated cardiovascular risk among adults with obstructive and restrictive airway functioning in the United States: a cross-sectional study of the National Health and Nutrition Examination Survey from 2007-2010. Respir Res 2012;13:115.

31 Li J, Agarwal SK, Alonso A, et al. Airflow obstruction, lung function, and incidence of atrial fibrillation: the Atherosclerosis Risk in Communities (ARIC) study. Circulation 2014;129:971-80.

32 Scarlata S, Pedone C, Conte ME, et al. Accuracy of spirometry in diagnosing pulmonary restriction in elderly people. J Am Geriatr Soc 2009;57:2107-11.

33 Hall C. NT-ProBNP: the mechanism behind the marker. J Card Fail 2005;11: S81-3 
34 Smith BM, Kawut SM, Bluemke DA, et al. Pulmonary hyperinflation and left ventricular mass: the Multi-Ethnic Study of Atherosclerosis COPD Study. Circulation 2013;127:1503-11.

35 van Gestel YR, Sin DD, Poldermans D. Elevated N-terminal pro-B-type natriuretic peptide levels: the effect of chronic obstructive pulmonary disease. J Am Coll Cardiol 2009;53:458-9.
36 Ramsay SE, Whincup PH, Papacosta O, et al. Inequalities in heart failure in older men: prospective associations between socioeconomic measures and heart failure incidence in a 10-year follow-up study. Eur Heart J 2014;35:442-7.

37 Wannamethee SG, Whincup PH, Lennon L, et al. Alcohol consumption and risk of incident heart failure in older men: a prospective cohort. Open Heart 2015;2: e000266. 